\title{
Os Impedimentos da Atividade de Trabalho do Professor na EAD
}

\author{
Alda Karoline Lima da Silva \\ Universidade Potiguar, RN, Brasil. \\ Camila Costa Torres \\ Universidade Federal do Rio Grande do Norte, RN, Brasil.
}

\author{
Jorge Tarcísio da Rocha Falcão \\ Universidade Federal do Rio Grande do Norte, RN, Brasil. \\ Gimena Pérez Caraballo \\ Universidade Federal do Rio Grande do Norte, RN, Brasil.
}

Resumo: $\mathrm{O}$ estudo apresenta uma análise clínica dos impedimentos da atividade de trabalho do professor na Educação a Distância (EAD) sob a ótica da abordagem teórico-metodológica da Clínica da Atividade (CA). Ser professor na EAD é uma atividade recente, comparada à modalidade presencial, na qual as atividades de trabalho são reconfiguradas tanto do ponto de vista técnico-instrumental quanto didático-pedagógico. A fim de estudar os impedimentos dessas atividades utilizamos a técnica da Instrução ao Sósia (IaS) para uma coanálise da atividade de trabalho. A análise da atividade de trabalho apontou diferentes formas de vivenciar os espaços de docência. As mudanças que a EAD produziu na atividade dos professores os convocaram a um acesso mais profundo das orientações genéricas da profissão, de modo a contribuir para revitalizações do fazer docente, não necessariamente atrelado ao uso do modelo presencial como um guia, pois replicar o modelo presencial para EAD não seria garantia do sucesso da atividade do professor na EAD.

Palavras-chave: Professor na EAD, Atividade Impedida, Clínica da Atividade.

\section{Work Obstacles for Distance Education Teachers}

\begin{abstract}
The study presents a clinical analysis of obstacles that Distance Education (DE) teachers experience from the standpoint of the theoretical and methodological approach of the Clinic of Activity. Being a DE teacher is a recent activity, compared to face-to-face modality, and work activities are reconfigured both from the technical-instrumental and didactic-pedagogic points of view. In order to study the work obstacles, we used the Instruction to the Double technique for a co-analysis of work activity. The analysis of work activity pointed out different ways to experience the teaching activity spaces. The changes that DE produced in the activity of the teachers called to a deeper access of the generic guidelines of the profession, in order to contribute to the revitalization of the teaching activity, not necessarily linked to the use of the classroom model as a guide, because replicating the classroom model for DE would be no guarantee of success for the DE teacher work.
\end{abstract}

Keywords: Teacher in Distance Education (DE), Activity Cancelled, Clinic of Activity. 


\title{
Los Impedimentos de la Actividad de Trabajo del Profesor en la EAD
}

\begin{abstract}
Resumen: El estudio presenta un análisis clínico de los impedimentos de la actividad de trabajo del profesor de la Educación a Distancia (EAD) desde la óptica del abordaje teóricometodológico de la Clínica de la Actividad (C.A). Ser profesor de EAD es una actividad reciente, comparada a la modalidad presencial, donde las actividades de trabajo son reconfiguradas, tanto del punto de vista técnico-instrumental como didáctico-pedagógico. Con el fin de estudiar los impedimentos de esas actividades, utilizamos la técnica de Instrucción al Doble para un análisis conjunto de la actividad de trabajo. El análisis de la actividad de trabajo mostró diferentes formas de vivenciar los espacios de docencia. Los cambios que la EAD produjo en la actividad de los profesores los invitan a un acceso más profundo sobre las orientaciones genéricas de la profesión, de modo a contribuir a la revitalización de la docencia. Esta revitalización no está necesariamente vinculada al uso del modelo presencial como guía, ya que replicar ese modelo en la EAD no garantizaría el éxito de la actividad del profesor en la EAD.
\end{abstract}

Palabras clave: Profesor de EAD, Actividad Impedida, Clínica de la Actividad.

\section{Introdução}

A atividade de trabalho como unidade de análise, preconizada por uma abordagem que abarca seu significado sociológico mais amplo, aponta que o ofício não existe apenas entre as profissões e/ou entre os profissionais, mas está em cada um deles. O sentido psicológico do ofício consiste em reconhecer-se em algo, reconhecer-se no que faz, estar seguro de sua utilidade social.

Para Clot (2010), vários gêneros profissionais podem convergir no íntimo de um mesmo ofício, ou até mesmo estar em conflito. O ofício faz parte do indivíduo quando ele assume a responsabilidade do ato, quando se vê através de cada um, mas sem se confundir. Envolve um apropriar-se dele, sem jamais ser seu proprietário, porque ele também é de todos os outros profissionais.

A docência no ensino superior é composta por profissionais de diversas áreas, que geralmente adentram nesse contexto em decorrência natural de suas atividades, transportam uma bagagem de conhecimento de suas áreas de atuação, muitas vezes não se questionando sobre o que é ser professor (Pimenta, \& Anastasiou, 2005). De modo semelhante, as Instituições de Ensino Superior (IES) já entendem que eles são professores. Essa concepção assemelha-se à noção antiga de ofício, que contempla a ideia de que este é ensinado com base no "fazer", e o aprendizado do fazer ocorre no exercício da atividade.
Dentre as problemáticas que assolam a docência no ensino superior, Pimenta e Anastasiou (2005) mencionam o suposto consenso de que a docência no ensino superior não requer formação no campo do ensinar. Além disso, pode-se apontar outro dilema, como a falta de orientação sobre os processos de planejamento, de metodologias e de avaliação, recaindo sobre o professor uma responsabilidade individual pelo seu trabalho. Por fim, a esses aspectos atrela-se a tendência de os professores assumirem cargos administrativos e de gestão sem a devida qualificação.

No entanto, a Educação a Distância (EAD), mesmo com todas as contradições em seu processo de ensino e aprendizagem, segundo Belloni (2012) destaca-se por contribuir para melhorar a educação enquanto processo de formação de professores. O alerta é não se limitar apenas a "instrumentalizar" o professor para usar Tecnologias da informação e comunicação (TIC) em suas práticas pedagógicas, mas prepará-lo enquanto usuário competente, crítico, criativo e participativo, a "começar por ele próprio".

Costa e Vallin (2014) apontam que uma das discussões centrais na $\mathrm{EAD}$ relaciona-se à mediação pedagógica enquanto aspecto inerente à prática da docência e, na maioria das vezes, responsável pela aprendizagem. Logo, a questão central que vem sendo ponto de discussão nas IES é o papel do professor 
nessa modalidade. Ser professor na EAD é uma atividade recente, com desafios e incertezas.

No contexto dessa nova atividade, as IESs têm um papel fundamental: criar condições que permitam aos professores vivenciar novas maneiras no processo de ensino-aprendizagem por esse outro meio. Há diferentes modelos de ensino e aprendizagem que a EAD concebe em seus projetos pedagógicos, produzindo distintas formas de uso no cenário educacional. Tal diversidade aparece em seus processos de trabalho, convocando toda a equipe pedagógica a repensar seus papéis diante dos modelos propostos. Nesse contexto, o professor, um dos principais protagonistas do processo, tem suas atividades de trabalho reconfiguradas tanto do ponto de vista técnico-instrumental quanto didático-pedagógico.

As reconfigurações da atividade de trabalho docente convocam a uma análise da atividade de trabalho, não somente pelas mudanças das atividades prescritas na profissão, mas sobretudo nos embates produzidos no "real da atividade" de trabalho, na qual destacam-se os impedimentos postos no fazer docente. Assim o estudo se propõe a fazer uma análise clínica da atividade trabalho, destacando notadamente os impedimentos da atividade de trabalho do professor nessa modalidade, sob a perspectiva da Clínica da Atividade (CA).

\section{Análise clínica da atividade de trabalho}

A CA é uma vertente teórico-metodológica da Psicologia do Trabalho, resultante de pesquisas e reflexões conduzidas por Yves Clot e por um grupo de colaboradores vinculados à perspectiva da Psicologia Histórico-cultural soviética (fundada por Vygotski), e da análise da linguagem proposta pelo Círculo Bakhtin. Essa abordagem considera o trabalho mais que a atividade explícita realizada pelo sujeito em seus espaços laborais, mas conta com o poder de falar e interpretar dos próprios trabalhadores, não se tratando apenas de "outras formas" de dizer, mas de outras coisas que poderiam ter sido ditas, e não foram.

Teixeira e Barros (2009) destacam que na análise clínica considera-se mais importante do que a coisa em si que foi dita ou do que o comportamento produzido, o processo implicado nas possíveis formas de dizê-lo, de interpretá-lo à luz das condições subjetivas do indivíduo, e das condições do meio em que ele atua. A CA propõe-se a estudar o trabalho como uma atividade dirigida e como uma função psicológica específica na vida do sujeito. Para Clot (2006), o trabalho é conside- rado uma atividade constante de recriação, envolvendo a criatividade sob novas formas de vivenciá-lo.

$O$ professor na EAD quase sempre desenvolve sua atividade a partir de sua experiência anterior de docência e dos contatos com artefatos tecnológicos virtuais. Seu saber fazer relaciona-se com o modo como foram vivenciadas essas etapas, isto é, com o que elegeu para fazer ou não. Aquilo que foi impedido, conscientemente ou não, se confronta com as demandas que a atividade docente lhe solicita. Nesse embate, a ação do professor não se concretiza somente via enfrentamento individual, mas se norteia por uma ação genérica que o respalda num grupo de profissionais. É dessa orientação genérica que os demais pares desenvolvem a atividade de trabalho.

A análise psicológica do trabalho é sempre análise do sujeito, de um grupo de trabalhadores, referente às atividades efetivamente realizadas ou impedidas dos sujeitos. De tal modo que a atividade impedida é o cerne de análise da atividade de trabalho. Destaca-se que a atividade de trabalho como o exercício coletivo de ligação social com o real da atividade convoca fortemente os trabalhadores a criarem e recriarem cotidianamente seus modos de trabalho e condições de vida.

Quanto ao trabalho do professor na EAD, é possível perceber que esse tipo de atividade o convoca expressivamente a pensar seus modos de atuação pedagógica, que geralmente advindo da modalidade presencial, depara-se com situações que lhe exigem o domínio de outras competências, ao lidar constantemente com a interatividade virtual como recurso essencial do seu fazer docente. Essa característica o convida a refletir coletivamente sobre a relação professor-aluno, a concepção pedagógica de ensino e aprendizagem que o circunda, e fundamentalmente sobre sua função (ou funções) nesse espaço.

\section{Os impedimentos da atividade de trabalho}

A atividade é uma estratégia de adaptação à situação real de trabalho, significa o trabalho efetivamente realizado, a forma pela qual o sujeito consegue desempenhar suas tarefas. A distância entre o prescrito e o real é a manifestação concreta da contradição sempre presente no ato de trabalho (Guérin, Laville, Daniellon, Duraffour, \& Kerguellen, 2001).

Para Montmollin (1990), a atividade é um processo complexo, em evolução, destinado a adaptar-se a tarefa, mas também com a função de transformá-la. Guérin et al. (2001) apontam que a tarefa não é o traba- 
lho, é o prescrito pela organização. A tarefa é exterior ao trabalhador, apresentando-se como um conjunto de prescrições impostas a ele. Os autores consideram que tarefa e atividade são aspectos indissociáveis do trabalho. Ao fazer uma distinção entre o prescrito e o real apontam que as condições reais de trabalho são sempre diferentes daquelas condições determinadas, os resultados efetivos são sempre, ao menos parcialmente, diferentes dos resultados antecipados.

Nesse espaço que vai do prescrito ao real, inúmeras (re)normalizações acontecem na atividade desenvolvida pelo sujeito. Clot (2006) acrescenta aos conceitos de atividade, tarefa, trabalho prescrito e trabalho real, advindos da Ergonomia, o conceito de "real da atividade", que se refere à atividade do indivíduo sobre si mesmo, consiste naquilo que pode ser feito, mas se escolhe, em determinadas circunstâncias (que podem mudar) não se fazer. $\mathrm{O}$ autor menciona que a atividade realizada é o que se faz, enquanto o "real da atividade" consiste também no que não se pode fazer, mas gostaria de fazer, e até mesmo no que se faz para não fazer aquilo que deveria ser feito, é no "real da atividade" que se encontram os impedimentos.

Há uma ruptura na atividade, entre as pré-ocupações dos sujeitos - planos, desejos e aspirações - e aquilo que são forçados a realizar - uma atividade prescrita pela organização, às vezes, vazia de significado (Bendassolli, 2011). Para Clot (2010), a perda de significado da atividade a desvitaliza. Logo, a impossibilidade de realizar um trabalho bem-feito ou de discutir sobre a qualidade do que se faz, impede os trabalhadores de se reconhecerem no próprio trabalho, gerando uma atividade vazia.

Segundo Bendassolli (2011), o desgaste no trabalho está relacionado ao que o trabalhador não pode fazer, e que gostaria, e àquilo que ele é forçado a fazer. Quando ocorre o impedimento, a energia associada à atividade acumula-se, sendo também este um fator de adoecimento, pois a saúde está ligada à intensidade dessa energia. A saúde relaciona-se à capacidade de recriação das situações, com desenvolvimentos inesperados, com a possibilidade de recriar o real do trabalho, por meio da autoiniciativa do trabalhador.

\section{Método}

A pesquisa em CA demandou a formação de um ambiente duradouro de análise, de colaboração (trabalhador e pesquisador), na qual os participantes da pesquisa estão empoderados a refletir sobre sua ativi- dade, e a partir disto poder transformá-la, convergindo com os pressupostos da pesquisa-intervenção, de modo que, como uma pesquisa clínica qualitativa, buscou-se fazer pesquisa "com" os professores e não "para" ou "sobre" eles. A CA pretende um acesso ao real da atividade pela análise da atividade de trabalho, esse acesso ao real é sempre indireto-mediado, na medida em que ele se dá via linguagem, via imagens registradas (videografadas) sobre a realização da atividade. Logo, é a análise do trabalho que vai possibilitar o acesso ao real da atividade.

\section{Participantes}

Realizou-se a análise da atividade de trabalho com dois professores da EAD, nomeados de Professor Regente (PR) e Tutor a Distância (TT) de duas IES distintas da cidade do Natal. Contemplou-se o critério de posição no ofício: um iniciante em $\mathrm{EAD}$ (há aproximadamente seis meses), e outro que atuava na EAD há mais de cinco anos, neste caso, desde a fundação do curso na sua Instituição, e exercia também a função de gestão.

Sobrea posiçãono ofício, Clot (2004) na análise da atividade profissional estabelece frequentemente uma distinção entre experte jeune débutant (jovem principiante) ou expert e débutant (principiante), ou ainda professionnel expérimenté (profissional experiente) e apprenti ou quase-apprenti (aprendiz ou quase aprendiz).

\section{Técnica de análise da atividade de trabalho}

Para a análise da atividade usamos a Instrução ao Sósia (IaS), técnica compatível teórica e metodologicamente com a CA. A IaS a surge como uma abordagem alternativa aos métodos de autoconfrontação, que não necessita dos recursos de coleta e edição de imagens videográficas, sendo usualmente escolhida quando há limitações no campo quanto ao uso de filmagem durante o desenrolar da atividade de trabalho, como no caso do professor em EAD. A técnica consiste em escolher uma atividade foco de análise na qual o pesquisador assume hipoteticamente a função de sósia, e o trabalhador a de instrutor. Em seguida, o pesquisador dá ao participante a seguinte questão: "suponha que eu sou seu sósia e que amanhã eu me encontro em situação de substituí-lo em seu trabalho. Quais são as instruções que você deveria me transmitir a fim de que ninguém se dê conta da substituição?".

$\mathrm{Na} \mathrm{IaS}{ }^{1}$ objetivou-se confrontar as instruções verbalizadas pelo sujeito, a fim de que ele pudesse comentá-las, inclusive, por escrito, se fosse conveniente - neste 
caso foi utilizada a videografia da entrevista de confrontação. É importante destacar aqui o papel que o pesquisador assume nesse método, que pode causar no sujeito um estranhamento em relação a sua atividade. Assim, ele, ao assumir o lugar de sósia, demanda um posicionamento de disponibilidade, de enfrentamento e insistência sobre o querer realmente apreender a atividade.

\section{Procedimento de análise}

A análise clínica foi organizada em dimensões construídas a partir do conteúdo discursivo dos participantes da pesquisa e dos pressupostos teóricos da CA, notadamente relacionados ao que foi contemplado na IaS, tais como "o que se faz habitualmente em sua atividade de trabalho, o que não se faz, o que não deveria fazer em hipótese alguma se for substituído, e o que ele poderia fazer, mas não faz" (Clot, 2010). As dimensões foram compiladas a fim de elucidar os principais aspectos do desenvolvimento da atividade docente na EAD.

\section{Resultados e Discussões}

As categorias de informações construídas a partir da IaS dimensionam uma análise clínica da atividade do professor na EAD, subdividindo-se em: a) O contexto da EAD: o processo de ensino-aprendizagem e seus atores; b) O papel do professor na EAD: o fazer habitual, as descobertas e os impedimentos da atividade; e c) Ser professor na EAD: os contextos de análise da atividade de trabalho. Para a análise, as falas dos participantes serão identificadas como PR (professor regente), TT (tutor a distância) e P (pesquisador), incluindo numerações antes da fala dos participantes da pesquisa, advindos do material de transcrição das IaS.

\section{Análise clínica da atividade de trabalho do professor que atua em EAD}

\section{a) O contexto da EAD: o processo de} ensino-aprendizagem e seus atores

Ser professor na EAD é uma atividade recente, quando comparada a atividade desenvolvida pelo professor no ensino presencial. Portanto, foi comum, nas entrevistas de IaS, os sujeitos reportarem-se à modalidade presencial como um guia para suas ações docentes de um modo geral. Tal característica é notadamente mais expressiva pelo docente cuja entrada no ofício é recente - "principiante" (Clot, 2004). Menciona-se no trecho: "[...] Tudo que eu sei da docência, do meu fazer de professor eu aprendi presencialmente [...]. Mas eu sempre me baseio...É como se meu grande chão fosse o presencial. A distância, eu estou apreendendo a fazer" (TT 50).

A entrada distinta no ofício fez com que a técnica tivesse direcionamentos diferentes quanto às instruções realizadas pelos docentes. O professor mais experiente iniciou sua instrução contextualizando o cenário da EAD, destacando o papel do aluno e do professor naquela modalidade. Enquanto o outro iniciou com a descrição de uma atividade mais técnica, como o acesso do professor a uma turma virtual, sendo seu relato inicial mais norteado pelo âmbito do prescrito (a tarefa).

Há convergências na fala dos sujeitos quanto ao que se espera do aluno nesse ambiente, conforme os enunciados PR 78 e TT 64 (ver a seguir). O formato de EAD presume um aluno com autonomia e que assuma uma postura mais ativa em seu processo de aprendizagem, uma concepção de ensino e aprendizagem na qual o estudante responsabiliza-se por muitas das atividades, que antes eram vistas como do professor (Litwin, 2001; Peters, 2004).

Na EAD, a principal dificuldade que eu vejo é daqueles alunos que não têm perfil para ser um aluno EAD. Para ser um aluno EAD precisa ter um perfil: ter disciplina, maturidade, desejo de buscar, de pesquisar, de ele mesmo procurar respostas [...] (PR 78).

[...] A distância, a gente trabalha com uma grande autonomia e muita maturidade do aluno para de fato responder, dar conta do que cabe a ele. É como se muito fosse delegado a ele, e aí eu não sei exatamente quem é esse ele que tá lá [...] (TT 64).

Logo, pode-se apontar que os atores no processo de ensino e aprendizagem na EAD são compostos por uma equipe multiprofissional (pedagógico, tecnologia da

\footnotetext{
${ }^{1} \mathrm{~A}$ IaS pode ser detalhadamente compreendida desde sua origem teórico-metodológica com Ivar Oddonne em 1970, até os procedimentos técnicos de uso retomados e desenvolvidos por Yves Clot em seus livros: "A função psicológica do trabalho" e "Trabalho e poder de agir" (Clot, 2006; 2010).
} 
informação, suporte técnico, entre outros), de modo que o papel do professor é reconfigurado a partir das interações que ele precisa desenvolver com os demais profissionais desse novo cenário de trabalho, que repleto de mudança produz novas exigências e posturas profissionais no fazer docente (Belloni, 2001; Litwin, 2001).

b) O papel do professor na EAD: o fazer habitual, as descobertas e os impedimentos da atividade

A atividade mais habitual dos docentes da EAD é o acesso às turmas virtuais. É por meio dessa atividade que a interface da relação professor-aluno materializa-se. Esse formato produz novas exigências aos docentes, pois não há um tempo e um espaço predeterminado (hora e local) para o ato de ensinar. Assim, há um redimensionamento no planejamento das atividades do professor nessa modalidade. Para o professor regente entrevistado, por exemplo, elimina-se cada vez mais a improvisação:

[...] ele precisa também estar consciente de que ele vai trabalhar com a EAD, e é bem diferente do planejamento que ele vai fazer, é diferente do planejamento da aula presencial. Na aula presencial, às vezes, o professor, na véspera, pensa numa atividade para aplicar no dia seguinte. $\mathrm{Na} \mathrm{EAD}$ é diferente. Ele tem que programar tudo com antecedência [...]. Então, as coisas não devem ser muito improvisadas, porque o aluno também tem que se programar [...] (PR 12).

Durante a entrevista com o professor regente, ele descreveu de modo geral as principais atividades do docente na EAD. Elegeu-se essa descrição como uma orientação que contemplou elementos fundamentais para a compreensão de desenvolvimento da atividade, em caso de "possível substituição ao sósia". A sistematização feita foi esclarecedora para compreender em termos de início e fim das ações docentes em uma turma virtual durante a semana.

Você poderia descrever algumas atividades que você tem que fazer? (P 42).

Algumas atividades que eu tenho que fazer: preparar o planejamento da semana, postar no ambiente virtual esse planejamento da semana, ou seja, esse planejamento começa pelo objetivo do estudo, qual é o objetivo daquela semana.
Em função desses objetivos, dizer quais as leituras que $o$ aluno precisa fazer e quais as atividades que o aluno precisa desenvolver [...]. Durante a semana, o professor e os monitores da disciplina acessam o ambiente diariamente, para acompanhar as atividades. Então, em geral, a gente abre um fórum de acompanhamento, [...] um fórum temático, de discussão, um chat, um questionário on-line, se for o caso. Então, durante a semana, o professor e os monitores ficam num ambiente em horários previamente definidos! Para tirar todas as dúvidas que nós temos, a política do aluno é não ficar mais de 24 horas sem resposta (PR 43).

Certo, então eu teria que qualquer atividade responder...? (P 44).

É, agora, assim, o professor e os monitores têm que estar muito afinados, porque por isso que ele tem que ser especialista naquela disciplina [...]. Se o aluno fizer uma pergunta ao monitor e ele não souber responder, tem que pedir socorro imediatamente ao professor, aí eles se comunicam e esclarecem (PR 45).

Entendi. É... Você falou que tem dias para entrar? Teria dias para entrar e tem dias que é... São objetivos que são postados a partir de... Para que o aluno possa entender ao longo da semana quais são suas reais atividades. Isso é sua forma de trabalho, ou uma forma generalista, onde todo mundo tem que fazer? (P 46).

Generalizada. Na nossa metodologia é assim: toda a disciplina... Isso aí, nós temos sistematizado e a gente entrega a cada professor. Toda sexta-feira, o professor deve postar as atividades que começam num sábado.[...]. Primeira semana, aí na sexta-feira seguinte ele coloca a atividade da outra semana, isto é, sistematizado (PR 47).

O professor regente, ao ser questionado se a forma de trabalho descrita por ele seria necessariamente um modo exclusivo de desenvolver suas ações docentes na $\mathrm{EAD}$, anuncia em seu discurso, especificamente no enunciado PR 47, uma orientação genérica e institucionalizada para "uma rotina" de trabalho, como um trabalhador que também é criador de prescrições. Nesse caso, esse aspecto pode estar atrelado a sua fun- 
ção de gestão. O sujeito, ao usar a terminologia "nossa metodologia", o pronome "nossa" funciona como sinalizador de características que são respaldadas por aqueles que compõem aquele grupo de profissionais. Até então, algumas atividades são similares ao seu fazer docente no ensino presencial, um dos principais diferenciadores é o artefato de mediação: o ambiente virtual de aprendizagem. A socialização com essa ferramenta é uma condição prévia para promover a interação professor-aluno.

O uso da ferramenta é uma habilidade que o profissional necessita desenvolver. Quando o professor, por exemplo, sentiu dificuldade em operar o sistema de acesso ao ambiente virtual, essa situação aparentemente produziu impedimentos concretos e observáveis no seu trabalho. Além dos impedimentos da atividade dessa ordem, há também aqueles do âmbito afetivo. Um dos sujeitos da pesquisa percebeu que os impedimentos com a atividade circundavam dois aspectos principais: a relação com o sistema informacional e o artefato mediador da interatividade professor-aluno, refletindo, assim, no próprio modo que a EAD coloca a relação professor-aluno.

[...] As questões que surgem no meu fazer docente é muito mais com o sistema, e essa relação com o aluno que é muito diferente (TT 26).

O que você acha diferente? Como eu perceberia que é diferente? (P 27).

[...] Quando você abre o fórum, você se decepciona, porque eles dizem assim: "É, realmente, o sistema não tem jeito!”. [...] É impossível, diante daquele material, daquelas referências, eles dizerem apenas isso, e então, assim, isso me incomoda, porque acho uma relação virtual muito econômica. Acho que poderia ser diferente. Uma relação que lhe dá prazer (TT 28 ).

Os trechos anteriores denotam como os sentimentos do sujeito diante de uma situação de decepção ou insatisfação afetam o vínculo professor-aluno. Na fala do sujeito, percebeu-se, mesmo que sutilmente, não apenas seu posicionamento didático-pedagógico diante da maneira de o aluno portar-se nas disciplinas da EAD, mas, notadamente, revelou em sua fala sua postura político-ideológica de conceber essa relação professor-aluno nesse formato de ensino: "uma relação virtual econômica".

A concepção da relação afetiva professor-aluno é retomada em vários trechos da fala do professor no decorrer da técnica, e o sósia-pesquisador, em alguns momentos, retoma o diálogo, com intuito de compreender como o sujeito percebe essa relação, na tentativa de explorá-la clinicamente (enunciado P71).

Como você acha que é diferente por exemplo? (P 71).

Não existe uma relação afetiva. Eles entram, perguntam qualquer questão como se a gente fosse um professor imaginário mesmo. Pronto, professor Gasparzinho. Pronto, agora vou mandar um e-mail pra ele! Diferente do professor presencial, o aluno, ele tem outra postura, ele chega: "Professor, eu posso falar com você? Olhe, eu tô com essa e essa dificuldade"; às vezes, a dificuldade que perdeu a prova ou porque perdeu trabalho. Existem algumas questões do fazer docente que vai acontecer nos dois ambientes, no presencial e no virtual. Mas existe uma forma diferente de se relacionar, eu acho que agora, conversando com você, eu começo a identificar. Essa forma de relacionamento me incomoda muito, é uma certa frieza e eu não sou fria com eles[...]. Mas é diferente! [...]. Ele espera muito da disciplina e qualquer dificuldade com o professor, a disciplina vai ser um caos. Mas no presencial a gente consegue... Identificando isso, a partir da aula, a gente consegue manejar. Se o docente for atento, ele maneja. Ele pensa metodologia, tem uma DR [Discutir a relação] com a turma, por exemplo. Com todas essas dificuldades, eu podia até abrir o fórum para a gente dialogar sobre isso, mas eu não sei a viabilidade institucional disso (TT 72).

Nesse momento da IaS, a dimensão clínica da técnica pode ser elucidada pela fala do professor, que elaborou ao longo do diálogo "descobertas" sobre ("eu acho que agora, conversando com você, eu começo a identificar") seu sentimento de incômodo na relação professor-aluno nesse modelo de EAD. Sua fala sobre a existência de um "professor imaginário", "gasparzinho", uma espécie de coisificação da relação, cujo vínculo se estabelece de modo não afetivo para aquele sujeito.

Portanto, o valor simbólico, humanístico e social do significado que a atividade docente representa para 
aquele professor é afetado ao assumir a condição de tutor da EAD, de modo a não se representar simbolicamente o vínculo afetivo da relação professor-aluno. Diante dos incômodos relatados pelo sujeito na relação professor-aluno, sinais de atividades impedidas são identificados, relacionados aos contextos pessoal (das inquietações do próprio trabalhador sobre seu papel docente) e interpessoal da atividade de trabalho (ao mencionar a frieza na relação com o aluno). Ao apontar uma possível forma de gerir esse desconforto, de imediato a anula, por não ter no âmbito impessoal (tarefa) e interpessoal (parceiros de trabalho) as orientações que legitimem sua ação - por exemplo, quando cita a possibilidade de abrir um fórum de discussão sobre o assunto, mas não sente segurança institucional para executá-lo.

c) Ser professor na EAD: os contextos de análise da atividade de trabalho

Ser professor em qualquer modalidade implica um envolver-se com o ofício. Logo, o significado atribuído à atividade é condição sine qua non para seu desenvolvimento. Esse significado abarca o processo de escolha, de identificação do sujeito para a atividade. $\mathrm{O}$ enunciado TT 24 exemplifica o docente não escolher esse lugar, que lhe foi imposto institucionalmente - aspecto que produz impedimentos, $\mathrm{e}$ muitas reflexões sobre o desenvolvimento da atividade de trabalho.

[...] uma disciplina a distância, o professor, ele tem que ter desejo de ministrar. Então, um belo dia eu abri meu sistema e estava lá a disciplina, fiquei louca! [...] Esse professor, ele tem que saber exatamente que modalidade é essa de ensino. Porque é outra modalidade. A disciplina é a mesma, mas eu vou ter que trabalhar em outro formato, outra metodologia, outro tempo, eu acho que pelo investimento, pela docência, é o mesmo, mas eu vou ter outras questões a pensar [...] (TT 24).

Ao longo do seu discurso, esse professor elaborou sua não identificação com o modelo proposto pela $\mathrm{EAD}$, apontou o quanto esse sentimento produziu impactos no seu fazer profissional. Como reconhece ter um perfil mais adequado ao modelo presencial, ele mencionou conflitos ao comparar as modalidades, deixando explícito seu posicionamento de reali- zação profissional na sala de aula convencional. "[...] A sala de aula é muito diferente porque é uma relação que acontece no ato, na hora. Talvez o meu perfil não esteja pronto para trabalhar com EAD. Eu me afeto muito mais, eu consigo produzir uma aula anos-luz melhor no presencial [...] (TT 64).

A identificação com a atividade docente sofre influência de vários sistemas de relações (sociais, econômicas, culturais, éticas), que fazem o sujeito se reconhecer e ser reconhecido na profissão. O modo como os sujeitos percebem a mesma atividade, o envolvimento que ambos investem em sua atuação na EAD mobilizam papéis de reconhecimento de si e da relação com o outro são distintos.

Por exemplo, no diálogo dos enunciados P 148 ao PR 155 (a seguir) com o professor regente sobre sua atuação docente, ao questionar sobre como seu estilo de trabalho no modelo presencial influenciava seu fazer na EAD, criou-se uma "expectativa pragmática" de que o discurso do sujeito fosse permeado pelo aspecto descritivo do comportamento, como assim foi no início da sua entrevista de IaS. No entanto, como característica típica dessa técnica clínica, uma gama de comportamentos não observáveis sobrepõe-se a uma descrição operacional da atividade.

Há na fala do sujeito um desvelar de elementos subjetivos das dimensões mais intrínsecas da dinâmica psicológica do trabalho, que se revela, naquele momento, para outro (sósia-pesquisador) que se disponibiliza a compreender sua atividade de trabalho, não a considerando "natural", mas assumindo uma postura empática quanto às hesitações e aos sentimentos do sujeito-professor perante seus afetos com sua atuação profissional. Para o professor, revelar seu desencanto com o ensino presencial e seu estímulo pela docência na $\mathrm{EAD}$ faz com que os sentimentos mais íntimos da sua relação com seu ofício sejam expostos, característica difícil de ser apreendida quando o sujeito não se mobiliza com a atividade proposta.

Você foi formada no ambiente para professor presencial, e foi modelando comportamentos para o sistema de ensino presencial, tem alguma coisa que você acha que é muito forte do seu modo de trabalhar no presencial que você leva para $\mathrm{EAD}$, ou você acha que dirimiu isso ao longo do seu tempo de docente? (P 148). 
Olhe! Eu já estou pedindo pra sair de lá pra ficar só aqui [EAD] (PR 149).

Você gosta mais desse espaço [EAD]? (P 150).

PR 151- Muito mais! Não tenho o menor receio de dizer[...] (P 150).

Ele me dá mais assim, liberdade de... Como é que eu poderia dizer? Dá até mais liberdade de horário. Você consegue se envolver mais, por incrível que pareça! [...]. Eu não sei se é porque atualmente estou desencantada em sala de aula presencial, eu estou numa fase meio... Isso aí pode está provocando um viés no que eu estou falando, entendeu? Estou extremamente desencantada com a atitude do aluno presencial. Esse que veio hoje foi um exemplo, isso aqui já é uma nova oportunidade da prova de reposição que o aluno fez e foi reprovado. Eu dei uma nova chance, aí vem e faz isso [mostra a prova] (PR 153).

Não fez nada?! (P 154).

Quer dizer, não é possível, eu fiz dez questões discursivas para dar a oportunidade a ele saber de alguma coisa, quer dizer, ele não sabe de nada que está ali. E nem se interessa! Então, eu estou numa fase assim... Meio desencantada [...]. Agora, nesse trabalho do artigo, teve muita gente que se envolveu muito, que mandava o questionário: professora dê uma olhadinha no meu questionário [...]. Aí, aquilo me envolve mais do que eu acordar, vir pra cá de sete da manhã para dar uma aula, de sete e vinte, sete e meia que os alunos chegam, com sono, sentados, você fala, fala, fala, e eles lá parados, aí eu pergunto: gente vocês entenderam? Não respondem nada! É uma apatia enorme, tudo bem, ou eu não estou sabendo mais dar aula. Mas como eu ouço os outros colegas reclamando também, mas eu ando desencantada com isso, e assim, a distância eu consigo me animar mais um pouco (PR 155).

Nesses trechos, o professor emite justificativas de âmbito individual (pessoal), referindo-se ao próprio processo de trabalho da EAD, possibilitando maior autonomia para organização de seus horários. Também se remeteu às relações com os parceiros de tra- balho, quando respaldou seu posicionamento sobre o perfil do aluno em seu contexto de trabalho no ensino presencial. Suas hesitações quanto aos "passos falsos" no trabalho docente - ao se indagar sobre "não mais saber dar aula no presencial" - o faz recorrer ao contexto interpessoal da atividade de trabalho, ao respaldar seu posicionamento afetivo sobre sua ação no modelo presencial em seus parceiros de trabalho.

O sentido que é atribuído à atividade de trabalho encontra-se arraigado ao desejo de pertencimento ao seu ofício profissional. E dentre as diversas variáveis que interferem no significado atribuído ao trabalho, aponta-se a concepção de "utilidade" - para si próprio e para os demais destinatários da atividade - como uma das características fundamentais para o desenvolvimento da ação do sujeito no trabalho. Lhuilier (2002) chama a atenção justamente para esse aspecto, explicando que o trabalho permite que o sujeito possa se sentir útil no mundo.

A sensação de atividade esvaziada, como apontaram os estudos em CA (Lima, 2007; Teixeira, \& Barros, 2009), faz com que o trabalhador envolva-se cada vez menos com a atividade profissional, seu poder de agir diante de uma ação "esvaziada" é atrofiado, fazendo o trabalhador sentir-se subutilizado. O discurso do professor regente ao elaborar seu "encanto e desencanto" com cada modalidade de ensino trouxe evidências de como cada espaço de trabalho o mobilizava afetivamente.

Os dois polos da sensação de esvaziamento da atividade de trabalho podem ser analogamente comparados às suas atividades no presencial e na $\mathrm{EAD}$, nas quais o raio de ação do sujeito se amplia ("a distância eu consigo me animar mais um pouco"), ou se atrofia ("É uma apatia enorme [...] ou eu não sei o que está acontecendo"), ao passo que seu investimento afetivo por cada modalidade é anunciado.

No que se refere ao relacionamento com os colegas de profissão, esse aspecto encontra-se influenciado pelos vínculos firmados com os colegas da modalidade presencial do professor-tutor sobre a interação com o coletivo de trabalho. Esse contexto interpessoal é permeado pelos destinatários da atividade de trabalho - no caso da EAD, podem-se mencionar de imediato os alunos e os professores, por exemplo.

E a relação com o coletivo de trabalho? (P 79).

Não tem. Isso é muito interessante! Eu só me relaciono com um colega da EAD porque é do curso... 
E aí, na verdade, a gente sempre conversa:"E aí, como é que tá as coisas?", "Ai, tô achando muito ruim, tô com muitas dificuldades...". Eu dialogo com ele porque ele é docente do meu curso, eu não dialogo com ele porque ele é docente EAD. Mas não existe esse espaço que os docentes possam estar discutindo, não existe! [...]. Pronto, fulaninho, ele é tutor há muito tempo, então nesse início eu convocava muito ele, eu dizia: "Venha cá, me diga como é isso no sistema, eu não vou poder ir lá no Núcleo agora..., Eu posso fazer isso?". Por exemplo, a estrutura das avaliações, ele foi quem me orientou, ele disse "Olhe, pense, porque seu tempo é muito pequeno, a turma é muito grande, se você colocar três questões subjetivas, eles já não vão ter tempo de responder [...]. Essa orientação dele, a experiência dele ajudou muito! E aí foi me orientando [...]. E aí tem outra coisa, falando com você eu lembrei agora. Eu acho que no ensino presencial você tem troca, você tem um retorno do aluno, afetivamente também, você sabe quando a aula foi muito boa, quando foi legal, e o aluno diz, e você dialoga, você vê o crescimento da turma. E eu me retroalimento muito disso, do que a gente tá construindo, do que a gente consegue discutir, dialogar. No ensino a distância, a gente não tem noção disso, é muito distante [...]. Acho que não é meu perfil! (TT 80).

O docente relatou que as trocas profissionais sobre atividade de trabalho ocorriam por meio da relação já estabelecida na modalidade presencial, o que não é surpreendente pela própria vinculação já estabelecida anteriormente, como também pela recentidade do modelo de EAD institucionalmente. No entanto, a ausência de um espaço, seja presencial ou virtual, impossibilitava que os trabalhadores envolvidos nessa atividade compartilhassem suas experiências.

As trocas entre os coletivos de trabalho possibilitam que os trabalhadores desenvolvam meios criativos de atender as demandas de seu meio profissional. E que a atividade individual desenvolvida por esses se ancore em uma história coletiva, a qual pode legitimar ou não suas ações. Portanto, estando isolados dessa troca com o coletivo, os trabalhadores tendem a afastar-se dos seus sistemas de orientações genéricas, e a vulnerabilizar-se como gênero profissional. Conforme apontou Clot (2010), o enfraquecimento dos coletivos de trabalho pode ser um indício de saúde-sofrimento no trabalho.

Retomando o desenvolvimento da atividade de trabalho do docente na EAD e, por conseguinte, o cenário das relações interpessoais, durante uma das entrevistas, ao questionar, como sósia, sobre possíveis dificuldades que teria como professor da EAD, a fala do professor regente é incorporada pela sua função de gestão. Então, ao tomar esse papel de coordenação, relata uma situação ocorrida sobre um problema que enfrentou com um docente:

Se eu, professor, tiver dificuldades de trabalho, a quem eu devo procurar? (P 178).

A mim. E aí a coordenadora tem que ter muito cuidado, porque tem uns professores que não querem que eu dê sugestão nenhuma, por acham que... Isso, no início, eu tive problemas seríssimos com determinado professor. Olhe, a gente estava no início, na segunda disciplina, e eu também aprendendo. Esse professor também não sabia nada de EAD, e eu: "Professor, olhe isso aqui [...] uma sugestão assim bem elaborada". Esse professor me mandou uma carta do tamanho do mundo, que não precisava ficar dizendo a ele como dar uma aula, porque ele já era mestre, doutor, que já tinha lido revista tal, não sei de onde, enfim, um "PhDeus" da vida. Imediatamente eu disse: "Professor, respeito os seus títulos, respeito suas publicações, vamos conversar pessoalmente?". Aí, finalmente ele veio, nós conversamos pessoalmente. Graças a Deus que nos tornamos grandes amigos! Até então, nós não tínhamos aproximação, mas foi uma coisa boa pra mim, porque... puxa vida! Eu tenho que ir com mais cuidado ainda do que eu fui, porque realmente tem professor que não quer que a gente sugira nada, nada! (PR 179).

O professor regente, após ser indagado pelo sósia, não entrou na esfera da "possível dificuldade" que o sósia podia enfrentar enquanto professor na EAD, ele adentrou na esfera da sua dificuldade, como assim a técnica possibilitou. Ele relatou uma situação conflituosa que enfrentou no início de sua carreira, dando indícios de como as relações de hierarquia nesse espaço são contempladas por pequenas sutilezas, típicas desse ofício de professor. O exemplo escolhido 
pelo docente foi extremamente ilustrativo para o ofício estudado, já que no cenário acadêmico, as relações de hierarquias não são estabelecidas somente pelos cargos ocupados nos organogramas institucionais, mas também pelas titulações e publicações que os docentes possuem, tais aspectos impõem respeito, admiração e status ao profissional.

Durante o processo de desenvolvimento da análise da atividade de trabalho do professor, um aspecto de extrema importância no emprego da IaS refere-se, notadamente, à utilização do espaço clínico da técnica. Em uma das entrevistas, ficou evidente a demanda do trabalhador para essa atividade reflexiva, fazendo jus ao uso do espaço como uma demanda do sujeito-trabalhador. Evidências de elaboração clínica apresentam-se quando um dos trabalhadores relata explicitamente mudanças em seus sentimentos no momento de confrontação.

Tem uma última questão que eu quero fazer com você: depois dessa experiência que você passou, você poderia apontar se mudou, ou não mudou a sua constituição de ser docente? (P 183).

Com certeza! Nesse momento que eu fiz o vídeo, os meus afetos estavam meio doídos, ao mesmo tempo que era uma confusão estar nesse lugar, definir esse lugar, compreender a minha identidade docente no lugar a distância. Era muito confuso, muito tumultuado, mas hoje, que a disciplina finalizou, que não estou mais a distância e que eu estou no presencial, eu não tiro nada do que eu disse. Só que essas questões que eu pontuei que doía, que era confuso, parece que estão elaboradas. [...] Nesse caso, quando vejo o vídeo, eu digo "é isso". Eu acho que as questões foram elaboradas, mas eu compreendi o que me afetou e nada vai me afetar com isso. Então, o que fica é que bom, me ajudou a compreender que esse não é o lugar que eu desejo ficar na minha docência (TT 184).

Você acha que para o professor [...] tem impacto de estar no presencial e a distância ao mesmo tempo? (P 185).

Tem. Se disser que aceita ou se não aceita? Sim, inclusive no futuro terá um grande impacto, porque hoje a gente pode escolher minimamente, mas vai chegar um momento que não terá possibilidades de escolha [...] (TT 186).

Então, já que você falou em respostas, eu queria agradecer a você. Essa técnica é uma técnica mais aberta, acho que você percebeu isso ao longo dos nossos encontros[...] Então, ver seu vídeo mobiliza muitas questões, e é muito importante ver que o sujeito se implicou, porque a ideia é ouvir a voz do trabalhador, e sua voz foi muito expressiva. [...] (P 187).

Eu, como sujeito da pesquisa, eu é que agradeço. Nesse momento que você me convidou, estava muito difícil pra mim mesmo. Eu cheguei a dizer: "Meu Deus! Eu não dou pra docência". Eu cheguei a questionar a minha identidade, as minhas escolhas. E eu quero the dizer que foi graças a sua pesquisa, naquele momento que a gente sentou, respirei e eu sabia que podia falar livremente, sem julgamentos, sem demissão, eu podia ser Maria (nome fictício). Assim, me senti Maria. Foi, assim, acolhedor; foi muito cuidadoso, por parte de você como pesquisadora, e o instrumento da pesquisa, que poderia dizer:"É aqui que eu vou me jogar, dizer tudo que eu penso"; e não só se jogar, porque quando a gente se joga e fala, a gente adora aquilo que nos está afetando. Que é o que eu acho que falta na instituição, em alguns momentos, falar no que nos afeta, isso gera um impacto e a gente sabe geralmente pra onde. [...]. Eu me questionei muito sobre o meu lugar, sobre essa instituição. [...] Eu que agradeço, foi um presente pra minha construção de ser docente que não esperava não! (TT - 188).

Os enunciados P 183 ao TT 188 remetem às evidências de elaboração clínica permitidas pelos métodos de análise da atividade. Além de evidenciar sinais de comportamento emocional do trabalhador, e de reflexividade sobre a atividade, a relação de coanalista mostra-se didaticamente compreendida nesse diálogo. O próprio trabalhador, no enunciado TT 188, fala da dimensão analítica da técnica, e do modo como se colocou como sujeito protagonista da pesquisa, tendo voz na problematização de sua realidade laboral. A migração de um lugar de "sujeitos" de pesquisa para o de coanalistas reflete a base primordial da Clínica da Atividade: ampliar o poder de agir dos trabalhadores, como coletivo e também sobre eles mesmos. 


\section{Considerações finais}

Percebem-se diferenças nas formas de conceber o papel docente pelos professores do estudo, notadamente, a problemática consistia na modalidade presencial como um guia norteador para as ações docentes de um modo geral, referindo-se tanto ao professor quanto ao aluno. Assim, há uma necessidade de mais estudos que enfoquem os papéis do professor, do aluno e demais instâncias envolvidas na EAD.

A própria recenticidade dos avanços da EAD convoca as IESs a pensar meios dos professores vivenciarem outras maneiras dos processos de mediação pedagógica no ensino-aprendizagem, condizentes com as concepções de educação postuladas em seus espaços pedagógicos. No entanto, esse movimento nem sempre é factível de realização. A recente inserção dos profissionais na EAD impõe um ambiente de desafios e incertezas.

Nesses casos, os contextos de desenvolvimento da atividade demonstram como suas ações nesses espaços estão em certa medida alargando não somente o leque de atividades prescritas para o gênero docente, mas as interfaces de outros modos de relacionar-se com os demais contextos, reconfigurando o modo de ser professor na atualidade. Referindo-se ao modo como o sujeito representou essa experiência na sua vida profissional, nas relações com o coletivo de trabalho, e como se instrumentalizou para tornar sua ação um ato individual para o âmbito coletivo. Esses contextos de desenvolvimento da atividade de trabalho para os professores da pesquisa são retratos das interações com suas interfaces da atividade de trabalho: história profissional (biografia), as relações com os destinatários da atividade, as tarefas, as regras explícitas e implícitas do ofício.

No que se refere ao aspecto clínico do método, esse materializou-se pela técnica da IaS, especifi- camente na relação entre instrutor (sujeito-participante) e sósia (pesquisador), no qual foi possível detectar sinais de comportamento emocional e de reflexividade no discurso dos professores. As evidências da elaboração clínica podem ser observadas em enunciados nos quais o sujeito elaborou a própria atividade de trabalho e seus impedimentos.

Em termos de desenvolvimentos e impedimentos da atividade de trabalho, ao longo da pesquisa foram mencionadas as situações e os meios de interações que cada participante estabelecia com sua atividade de trabalho. Assim, pode-se afirmar que nos impedimentos da atividade, para além do obstáculo (sistema) - do âmbito da objetividade -, estava presente uma vertente interna, que nessa situação dizia respeito da relação desse professor com a EAD, traduzia suas inquietações e ansiedades.

Nesses casos, a ampliação do poder de agir passava pela tomada de consciência desse trabalhador sobre sua relação com a EAD, que repercutiu em uma ação, um professor (tutor), após análise da sua própria atividade, decide não mais atuar na $\mathrm{EAD}$, por exemplo. Enquanto o professor "regente" não gostaria mais de atuar na modalidade presencial. Observamos assim a importância de criar espaços onde o trabalhador possa falar da sua atividade e possa refletir sobre ela, tornando-se um agente ativo na análise dessa atividade e dos impedimentos do fazer profissional.

A pesquisa nesse campo da EAD necessita de continuidade pelo próprio escopo do estudo que abarcou uma realidade específica, e limitações da própria análise clínica do trabalho a qual tem propósitos específicos de análise do real da atividade e seus impedimentos, não abarcando uma discussão mais macro no que tange a EAD enquanto uma modalidade de educação a ser debatida no cenário contemporâneo.

\section{Referências}

Belloni, M. L. (2001). Educação a distância. Campinas, SP: Autores Associados.

Belloni, M. L (2012). Educação à distância e mídia-educação: da modalidade ao método. ComCiência, (141). Recuperado de http://comciencia.scielo.br/pdf/cci/n141/n141a10.pdf

Bendassolli, P. F. (2011). Mal-estar no trabalho: do sofrimento ao poder de agir. Revista Mal-estar e Subjetividade, 10(1), 63-98. Recuperado de http://www.pedrobendassolli.com/textos/mal-estar.pdf

Clot, Y. (2004). Action et connaissance en clinique de l'activité. @ctivités, 1(1), 23-33. https://doi.org/10.4000/activites.1145

Clot, Y. (2006). A função psicológica do trabalho. Petrópolis, RJ: Vozes.

Clot, Y. (2010). Trabalho e poder de agir. Belo Horizonte, MG: Fabrefactum. 
Costa, J. R., \& Vallin, C. (2014). Pressupostos teóricos para a docência na ead: reflexões preliminares acerca da mediação pedagógica. InterScience Place, 1(28), 160-171. Recuperado de http://www.interscienceplace.org/isp/ index.php/isp/article/view/275

Guérin, F., Laville, A., Daniellon, F, Duraffour, J., \& Kerguellen, A. (2001). Compreender o trabalho para transformá-lo: a prática de Ergonomia. São Paulo, SP: Edgar Blücher.

Lhuilier, D. (2002). Travail. In J. Barus-Michel, E. Enriquez, \& A. Lévy (Eds.), Vocabulaire de psychosociologie (pp. 284-295). Toulouse: Erès.

Lima, M. E. A. (2007). Contribuições da Clínica da Atividade para o campo da segurança do trabalho. Revista Brasileira de Saúde Ocupacional, 32(115), 99-107. https://doi.org/10.1590/S0303-76572007000100009

Litwin, E. (2001). Das tradições a virtualidade. In E. Litwin (Org.), Educação a distância: temas para o debate de uma nova agenda educativa (pp. 13-22). Porto Alegre, RS: Artmed.

Montmollin, M. (1990). A ergonomia no trabalho. In M. Montmollin (Org.), Ergonomia (pp. 29-46). Lisboa, Portugal: Instituto Piaget.

Peters, O. (2004). A educação a distância em transição: tendências e desafios. São Leopoldo, RS: Unisinos.

Pimenta, S. G., \& Anastasiou, L. G. (2005). Docência no ensino superior. São Paulo, SP: Cortez.

Teixeira, D. V., \& Barros, M. E. B. (2009). Clínica da atividade e cartografia: construindo metodologias de análise do trabalho. Psicologia \& Sociedade, 21(1), 81-90. https://doi.org/10.1590/S0102-71822009000100010

\section{Alda Karoline Lima da Silva}

Doutoranda pela Universidade Federal do Rio Grande do Norte (UFRN). Docente da Universidade Potiguar ( UNP). Mestre em Psicologia pela UFRN, Natal, RN, Brasil.

E-mail: aldakarolinel@yahoo.com.br

\section{Jorge Tarcísio da Rocha Falcão}

Docente da Universidade Federal do Rio Grande do Norte (UFRN), Natal, RN, Brasil. Doutorado em Psicologia em Université Paris Descartes, Paris 5, França.

E-mail: falcao.jorge@gmail.com

\section{Camila Costa Torres}

Docente da Universidade Federal do Rio Grande do Norte (UFRN), Natal, RN, Brasil. Doutorado em Psicologia (Conceito CAPES 5) pela Universidade de Brasília, Brasília, DF, Brasil.

E-mail: pcamilatorres@gmail.com

\section{Gimena Pérez Caraballo}

Pesquisadora associada da Universidade Federal do Rio Grande do Norte (UFRN), Natal, RN, Brasil. Doutorado em Psychologie Interculturelle pela Université Lumière Lyon 2, França.

E-mail: gimenaz@gmail.com

Endereço para envio de correspondência:

Universidade Potiguar, Mestrado Profissional em Psicologia Organizacional e do Trabalho. UNP

Avenida Engenheiro Roberto Freire, 2184. Capim Macio. CEP: 59082-902 .

Natal - RN, Brasil.

Recebido30/11/2015

Reformulação 22/08/2016

Aprovado 10/02/2017 
Psicologia: Ciência e Profissão Jul/Set. 2017 v. 37 n³, 683-696.

Received 11/30/2015

Reformulated $08 / 22 / 2016$

Approved 02/10/2017

Recebido 30/11/2015

Reformulado 22/08/2016

Aceptado 10/02/2017

Como citar: Da Silva, A.K.L.; Falcão, J.T.R.; Torres, C.C.; Pérez Caraballo, G. (2017). Os impedimentos da atividade de trabalho do professor na EAD. Psicologia: Ciência e Profissão, 37(2), 683-696.

https://doi.org/10.1590/1982-370304162015

How to cite: Da Silva, A.K.L.; Falcão, J.T.R.; Torres, C.C.; Pérez Caraballo, G. (2017). Obstacles in labor activity for distance education teachers. Psicologia: Ciência e Profissão, 37(2), 683-696. https://doi.org/10.1590/1982-370304162015

Cómo citar: Da Silva, A.K.L.; Falcão, J.T.R.; Torres, C.C.; Pérez Caraballo, G. (2017). Los impedimentos de la actividad de trabajo del profesor en la EAD. Psicologia: Ciência e Profissão, 37(2), 683-696. https://doi.org/10.1590/1982-370304162015 